\title{
Politics of Identity and Power Distribution in Practice, Pedagogy, and Curriculum: Personal Reflections of Teacher Supervisors in Morocco
}

\author{
BRAHIM KHARTITE 19 (D) ELHABIB ELHADARI ${ }^{2}$ (D) and ABDERRAHMANE BABNI ${ }^{3} \mathbf{8}$ \\ ${ }^{1}$ ENSAM -Mouly Ismail University- Meknés, Morocco \\ ${ }^{2}$ Faculty of Letters and Human Sciences, University Sultan Moulay Slimane Beni Melal Morocco \\ ${ }^{3}$ Assistant Professor, Polydisciplinary Faculty, Errachidia Moulay Ismail University, Morocco \\ $\triangle$ Corresponding Author: BRAHIM KHARTITE, E-mail: brahimkhartite@gmail.com
}

\section{ARTICLE INFORMATION}

Received: June 04, 2021

Accepted: July 09, 2021

Volume: 1

Issue: 1

DOI: $10.32996 /$ ijls.2021.1.1.4

\section{KEYWORDS}

Identity markers, Power and Knowledge, Unequal Distribution of Power, Classroom Practices, Pedagogy and curriculum

\section{ABSTRACT}

An educational system that aspires to be effective would constantly strive to bring about positive change into the society and the students it is meant to serve. Attending school would amount to a waste of time unless the experience manages to make a difference in the students' lives regarding how they view themselves and the others around them.After all, education is not about stuffing students with knowledge; it is mostly about inspiring and empowering young learnerswith the knowledge that being different-with regards to gender, skin colour or social class does not necessarily amount to being inferior. The aim of this reflective report is threefold. First, it tries to identify the relationship between knowledge and power.It will also elaborate on the concept of identity as a socio-cultural construct with deep implications for classroom practices, before closing with an investigation into how students and teachers' complex and diverse identities interact and shape the knowledge and power constructed in classroom practices, pedagogy, and curriculum. As implications, the paper concludes with the idea that there are yet a number of teacing and learning aspects to be explored before the classroom becomes a space where various identities are equally valued and recognized instead of a space where a sense of unequal distributon of power (and steriotypes unfairly associated with some identities) is maintained and perpetuated.

\section{On the Relationship Between Knowledge and Power}

As early as the $16^{\text {th }}$ century, Francis Bacon, (EnglishLawyer and Philosopher. 1561-1626) stipulated that "knowledge is power". Similarly, Ralph Waldo Emerson (AmericanPoet, Lecturer and Essayist, 1803-1882) later phrased the same idea differently when he stated that "There is no knowledge that is not power." This implies that behind every form of power there is a form of knowledge. For example, parents and teachers have more power over their children and students because they are more knowledgeable. Expert in all domains tend to enjoy more power than ordinary people because they are assumed to be more knowledgeable and therefore likely to make more informed decisions and accurate choices about others lives. Power and knowledge feed into each other; the more knowledge one has the more power they enjoy

In his introduction to The Archaeology of KnowledgeM. Foucault (1972)summarized his conception of knowledge and power relationship stating that "those who have power to produce knowledge have the truth and they can inflict meaning on language and then just produce the type of knowledge they want" (227). He relates knowledge production to certain discursive formations within which the subject (the person) of language is regulated and then made. For example, a ball is just a ball. But once thrown in the stadium it becomes what people want it to be. It is the subject of rules put by those who make the game.

Yet before going any further, it is only fair to discuss first what is meant by power and how it functions. As it is used in the present paper, power describes the ability to make choices, to make decisions, to change and/or question the status quo, to

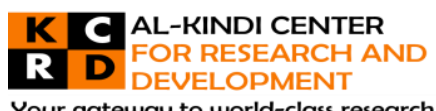

Your gateway to world-class research

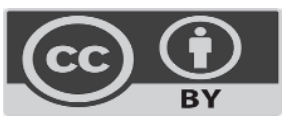

Published by Al-Kindi Center for Research and Development. Copyright (c) the author(s). This open access article is distributed under a Creative Commons Attribution (CC-BY) 4.0 license 
have a voice and talk for oneself / also known as self -Representation in order to be heard and (hopefully taken seriously). It seems especially that having power describes aboveall the ability to produce knowledge (theorizing, teaching others and spreading one's views and ideas about the world). This means that knowledge and power are very intimate inseparable concepts. The mention of one entails the presence of the other. Knowledge is not only a source of power, but a product of it as well. The same thing rings true for power which is both a source of knowledge and a product of it.

In this paper, power is about one's ability to carry out their own will. This is reminiscent of Weber's definition of power as "the chance of a man or of a number of men to realize their will in a communal action even against the resistance of others who are participating in the action" (as cited in Gerth \& Mills1991, p. 180). Some of the questions this paper addresses are: to what extent is this individual will respected when power is distributed in classroom practices, pedagogy and curriculum?What role do gender, skin color and social status have in the process of power distribution? Does the knowledge teachers have and produce empower students or enslave them? Does the way students are taught and the curriculum is implemented enable them to carry out their will and make their choices and decisions?And is the relationship which binds teachers to students a power-to or a power-over relationship?

Textbooks serve as an important tool to present and organize EFL curriculum. A simple scrutiny of a sample unit of a Moroccan EFL textbook can help us have an idea about how gender and skin color are represented and how these representations can impact power perception and distribution in Moroccan classrooms and schools.For instance, in unit 2 in Focus textbook, the names of females outnumber those of males (fourteen females vs. eight males). The same remark is true for the twenty-three pictures used in this unit (fifteen females vs.eight males).Twenty-two of the people in the pictures are white and just one girl is black. These statistics reveal that the linguistic and socio-cultural knowledge presented in this unit is gender and skin color biased. Some power is, intentionally or accidentally, given to females over males and whites over blacks.

This kind of biased knowledge may engender an atmosphere of tension among very young learners/ teenagers, especially if the content of the unit is taught to the letter without any reflective evaluation and adaptation. The danger in this is that too much space is dominated by female voices and white characters. This can even develop into hatred and violence. Some males and blacks may feel psychologically shattered and may possibly think of ways to challenge females and whites, frantically voice their opinions and realize their own wills; they may also be less willing to learn as they may feel that they are inferior to others. We think that teachers need to intelligently handle this sort of situations by adapting this knowledgeto their teaching/ learning environments in a way which can create some power equilibrium at the level of gender and skin color.

One more thing, when less space is devoted to the process of personalizing learning in classroom practices and EFL curriculum, the knowledge presented and produced in the classroom turns out to be a force of enslavement and imposition and not of empowerment and enlightnement. Both teachers and learners become slaves of this knowledge. Instead of having choices and decisions made and personal voices heard, the room gets wide open for the creation of a generation of conformists who excel at nothing but fulfilling others' wills and not theirs. We can say that one of the big risks educators have to address and deal with is to fight back any bids to depersonalize teaching and learning. When teaching and learning are depersonalized, both teachers and learners are bereft of their right to develop their own personal identities.

Personalizing classroom practices, pedagogy and curriculum is an important step forward toward enabling young learners to think and act in terms of their individual 'I' rather than their communal 'we,' to use the words of Esteva et al. (1998, p. 51). It's a sort of mirage to talk about learners' empowerment in the absence of their individual identities. We believe that favouring a gender or a color over another in a textbook, albeit unconsciously, is a real threat to learners' personal identities. It's time to stop seeing our learners taking bullets for the textbook designers and EFL practitioners.The worry about what Hartman (2001) refers to as becoming "immersed in the other" (74) should be a top priority for educators in Morocco. The other in unit 2 in Focus is the female gender and white race. We don't want our students to be immersed in each other.

\section{Knowledge and Power Seem Justify Each Other}

The ability to produce knowledge is one ultimate manifestation or aspect of powe. It is not without relevance to note that those who have power will produce only knowledge that would justify and perpetuate their power. In other words, those who enjoy the privileges associatedwith power and dominance will not venture to produce knowledge that would threaten their power. On the contrary, the type of knowledge they will tend to produce- and do everything they can to inculcate in the mind of ordinary individuals-is that which justifies their position. Their discourse will almost exclusively be geared to establish the fact that things cannot be otherwise or at least any better than they are.

Knowledge/power dichotomy has a hermeneutical dimension that should not go unnoticed.It is the interpretation of both knowledge and power. This interpretation differs from one individual to another. In this vien,Edward Said (as cited in Saidi, 2010, p. 10) says: 
All knowledge that is about human society, and not about the natural world, is historical knowledge, and therefore rests upon judgment and interpretation. This is not to say that facts or data are nonexistent, but that facts get their importance from what is made of them in interpretation... for interpretations depend very much on who the interpreter is, who he or she is addressing, what his or her purpose is, at what historical moment the interpretation takes place.

. In the field of English language teaching and learning, plociy makers, curriculum designers, commercial lobbyists and teachers are owners and interpreters of knowledge and power in educational institutions. The power they have entitle them to control the kind of knowledge kids can access. In other words, They can choose what should be said and what should be left unsaid because the audience they address are very young learners who are ready to listen to them and obey their orders. They have ample power over kids to decide the type of knowledge to highlight or discard. They are very selective regarding the people they choose to give a voice to and those they would prefer to silence or marginalise as irrelevant or even a nuisance. More importantly, people who have the upper hand on the domain of education can use their power to define the kind of knowledge to create to serve their purposes.

At schools in general and the classroom in particular, teachers, knowingly or unknowingly, choose, in one way or another, what their students should be told and untold. They can have their own hidden aganda; they can decide on the kind of knowledgevalues, concepts, beliefs and skills- to highlight or dismiss as 'irrelevant'. They can give a voice to some students and silence or marginalize others. The feedback they give to theirstudents and the kind of interactions they opt for in their instruction mode can take some to the top of the power pyramid and place others at the bottom.

Similarly, textbook authors and curriculum designers in their turn enjoy the same amount of power, if not more. It is the power ofdefining the teaching/learning content for their textbooks; they make every single decision about this content- the pictures, figures, themes, topics and above all individuals- by choosing thekind of knowledge (topics)to be learned and even thetype of questions to be asked. Luckily though, it is comforting to realize that when teachers implement the text book and teach the syllabus, they have a final say as to the kind of examples to illustrate, the kind of concepts to focus on, the values and/or views to debate and highlight in the classroom. This is to stress the idea that the textbook in the long run is just a project for implementation. Using it requires some creativity, innovation and imagination on the part of teachers. It does also require considering the human dimension of power relations in the classroom. Any abuse of power can result in the misuse of the content of the textbook and the disequilibrium in the proceeding of classroom practices.

\section{Knowledge/Power vs.Politics of Identity}

In this paper, identity refers to what makes an individual or a group of individuals dissimilar and special in comparison to others. They might have some attributes in common; yet, certain qualities are specific to some individuals and groups.To put it differently, identity is the sum of idiosynchratic features which distinguishindividuals and communities from each other. We believe that the main job of schools and curricula is to help learners discover their identities and develop them.The knowledge and power of educators should be geared towards helping kids undertake the journey of finding answers to the question of who they are.

This is to suggest that the content of the curriculum, the classroom environment and the pedagogyused can help or hinder students' endeavors to have a sense of who they are. Schools in general and classrooms in particular should be warm enough for students to feel at home. Self-discovery requires this warmth which itself requires productive and constructive knowledge and power. When kids feel intimidated, they get overwhelmed with a strange feeling of estrangement. We think that real knowledge and power should aim at making them feel that they belong to their schools.

Bauman (1996, p. 19) relates identity to people's sense of belonging, self-placement and feelings of uncertainty: "one thinks of identity whenever one is not sure of where one belongs". If students don't feel that they are part of the place where they learn, they grow uncertain about who they are. The more this uncertainty prevails, the less successful educators are. Real knowledge and power should serve the purpose of straightjacketing this uncertainty and facilitating the kids' task to appropriately place themselves right.

Culture lies at the very center of identity contruction and reconstruction. It includes the attitudes and behaviours that are characteristic of a particular social group or organization. Going back to the classroom, it is interesting to notice how students and teachers who come together in one class are never and can never be totally homogenous. Classrooms reflect symbolic spaces where various identities and cultural backgrounds come to play but are not equally recognized as having the same value or degree of significance. Hence the big importance of establishing a third space where these cultures can meet and co-exist. 
This space can be createdonly when knowledge introduced in classrooms and power practised at schools belive in the value of this third space whichPapastergiadis describes as a "lubricant in the conjunction of cultures" (qtd. in Ikas, 2008, p. 131). This lubricant can enable her to cope with any possible "misunderstandings occurring in interactions across languages and cultures" (ibid).

Aronson et al. (2010, p. 118) point out that when people are asked to answer the question of who they are, the child's answer is different from that of a teenager, an adult, or an elderly person. This is to say that different variables can interfere in the process of self-definition such as age, gender, birthplace, work, hobbies and interests, religion, skin color, race, socio-cultural upbringing, other's judgements, life experiences, social customs and beliefs, and physical appearance. We think that the main mission of schools and curricula is to enable kids to clearly define themselves and develop some sort of self-awareness. We need knowledge and power which lead toward the fulfillmentof this mission.

Finally, part of one's identity is what makes him/her different from 'others'. This implies that there are layers of identity. These can be referred to as identity markers. People tend to differ across such identity markers as gender, social class, skin colour, cultural and ethnic or religious backgrounds etc. Nowhere else do all thesediscrepant identitiescome into close contact and thus interactwith each other almost on a daily basis than in the classroom. Therefore, one is tempted to ask if these identities are equally highlighted in the teaching material and whether they enjoy equal status or power in pedagogy practice and curriculum?

The answer is no. For there are yet teachersof English as a foreign language who would see no harm to holda picture of white woman with long and blond hair to teach the word 'beautiful'. There are yet teachers who would teach the past continuous using such examples as "my mother was cooking lunch when my father was reading a newspaper." There are yet others who would ask students (usually at the beginning of the year) about their father's job to understand what type of social class they are dealing with. There are also those who teach comparatives by asking students questions like "which language is more important to learn English or Arabic?. Knowingly or unknowingly, this kind of questions- that are meant to maximize ineraction- merely reinforcing in the students' conception the idea that some language are inherently important to learn whereas other are just awaste of time and energy.

All these teachers cannot claim to be fair to other identities in their language class. In the same vein, a teacher referring to the mother as someone who is always doing the house work while the father as someone doing the thinking or intellectual work (decision making) is just as unfair to the rest of women around the world. For thisis going beyond teaching a mere grammatical structure to deliberately (knowingly or unknowingly)attempt tomaintain a state of unequal power distribution in terms of gender.

Implicitly, examples like those cited above are perpetuatingconventionally established constructs/or knowledge regarding what males and females can play as roles beyond the classroom, which ethnic group can be described as beautiful or not beautiful, which jobs are deemed respectful and which jobs are associated with the lower class and therefore the students coming from those families might be a source of threat and very little can be expected in terms of their school achievements. We think that teacher'bias accounts for a great deal of what students can or cannot achieve in their class. This bias, itself dictated by the type of identity involved, will tend to shape teachers' expectations from various identities they happen to have in their class and thus eventually affect their students' performance and in the long run their achievements as school clients.

\section{Bringing the Concepts of Knowledge, Power and Identity Together}

We assume that the relationship between knowledge, power and identity becomes obvious when one thinks about how certain identities are inherently endowed with power - which is just another way to say the word privileges that others are denied. In other words, while identity is based on the difference from "us" as a dominant group, difference in itself has no value. Rather, it is the unequal distribution of power among identity markers that is at issue. Saying that power is unequally distributed implies in one way or another that some identities are conventionally regarded aspowerful and others are widely unwanted because they evoke some undervalued qualities or undesired identity markers. For example a baby boy born into a patriarchal society would enjoy more privileges and/or power than a baby girl.This evokes the bottom line of this paper that these male-oriented attitudes and patriarch-cal practices are often maintained and perpetuated via the type of knowledge disseminated at schools and more so via everydayclassroom practices. Some identities are endowed with privileges that others are denied. From these identity markers emerge dichotomies in terms of identity markers or layers:

\begin{tabular}{|ll|}
\hline Identity Markers & Dichotomies \\
\hline Language & Arabic/Berber vs. English/French \\
\hline Social class & Rich vs. Poor \\
\hline Gender & Male vs. Female \\
\hline Skin colour & White vs. non-white \\
\hline
\end{tabular}




\begin{tabular}{|ll|}
\hline Religion & Muslim vs. non-Muslim \\
\hline Educational background & Literate vs. illiterate \\
\hline Culture & Natives vs. non-natives \\
\hline
\end{tabular}

\section{Implications and the new roles of EFL Teachers and Textbook Designers}

Coming back to the classroom, the a forementioned reflections on classroom practices have a plethora of implications for teachers, material creators, curriculum designers and policy makers:

- Classroom practice: tasks, role plays, activities, and illustrations or examples used to illustrate points should be evaluated and reconsidered to make them bias-free;

- Classroom language:examples and questionsaskedto make new concepts and new learning accessible and more meaningful should be part of the design and planning stages;

- Learning opportunities or educational activities and designed for classroom implementation must take all the above identity markers into account;

- Efforts should be joined to avoid all tasks and activities which can marginalize vulnerable groups and minorities who are already marginalized in society beyond the borders of the classroom. Schools and curricula are spaces where inequality and unfair distribution of power amongst identity markers must be questioned and not perpetuated and reinforced;

- As teachers, we should attend to our everyday classroom practices to ensure that we are not merely maintaining the unequal distribution of power that is already deeply rooted among discrepant identities. Instead, we should be the agents of change we want to see in society by ascertaining that this unequal distribution of power with regards to Identity markers is not reinforced or maintained at schools via the textbook content, everyday teachers' classroom practices/language and illustrative examples

After all, if the ultimate goal of schools and education in general is to bring about positive change and to make a difference in the lives of individuals, then the classroom is an ideal platform where any sort of inequality between identity markers has to be examined and reconsidered and not disseminated and circulated all over the place because:

$\checkmark$ Teachers are responsible for the kind of knowledge that is created or reproduced in the classroom; they need to make sure it is not geared to accentuate the state of unequal distribution of poweramongst school goers and this is especially so for those who already suffer outside the classroom;

$\checkmark$ Personalizing teaching and learning is almost a must. Students' personal identities cannot be solidly reinforced if their individual 'I's are marginalized at schools and in the classroom. To create a generation of people who can make choices and take decisions, it is very important to stop depersonalizing learning and teaching. This simply means connecting the content of the curriculum and pedagogical practices to the personal lives of students;

$\checkmark$ Teachers' examples are at times biased against or in favour of certain identities; this requires some peer observations so that teachers can provide feedback for each other on the extent to which their teacher talk is fair and unbiased;

$\checkmark \quad$ It is no longer enough to adapt activities and tasks in terms of difficulty to make them match the proficiency level of the students. Nor is it enough to adapt them in terms of relevance to students' needsand interests. Adaptation means also figuring out ways to ascertain that different groups and identities are equally represented and evenly recognized in curriculum, practice and pedagogy;

Teacher supervisors need to go beyond teaching methodology and lesson planning to scrutinise every educational activity, task or illustrative example in the textbook used in the classroom by teachers they observe to make sure:

$\checkmark$ what kind of identity markers are mentioned and how are they represented;

$\checkmark$ how the unequal distribution of power with regards to Identity Markers is reinforced, maintained or questioned and dealt with cautiously.

$\checkmark \quad$ which identities are mentioned and whicharediscarded and for what purpose? What is said and what is left unsaid?

$\checkmark$ which group is given a voice and which group is silenced or given a mere secondary role;

$\checkmark$ the extent to which the power and knowledge teachers have is used appropriately and constructively; 
$\checkmark$ there is a power-to relationship between teachers and students;

$\checkmark$ the textbook is not used to the letter; rather, it is used creatively and innovatively;

$\checkmark$ there is no abuse of power and misused of knowledge;

$\checkmark \quad$ they have a role to establish an atmosphere of justice, equality and equity at schools and in classrooms;

\section{Conclusion}

The hope of this refelective paper is to have made it clear how concepts such as power knowledge and discrepant identities or identity markers implicitly or explicitly come to a constant play in everyday classroom practices, pedagogy, and curriculum. It is especially hoped that teachers would attend more to their everyday classroom practices, improvised examples, conventionally established role-plays assigned to individual students and above all, their bias against or in favour of certain identities in their class. As well, curriculum designers and textbook writers have an obligation to represent various identities, give voices to historically silenced minorities and make sure the power is equally distributed among identity markers as reflected in each and every individual in a healthy, fair and even-handed teaching and learning environment.

It was the ultimate goal of this paper to provide a perspective on the concepts of identity, knowledge and power in classroom practices, pedagogy and crurriculum from the points of view of ELT supervisors in Morocco. In future research, teachers can be invited to have their say in the way these concepts come to play in their classrooms. This work is just a milestone in the course of finding out more about what actually happens in the classrooms. Its trajectory has been set with the desire to humbly reflect on the kind of relationships which bind students to their teachers and curriculum at schools as spaces of power and knowledge. There are still a lot of things to be explored and unearthed about this topic before the claroom becomes a space where various identities are equally valued and recognized and not one where a sense of unequal distributon of power and steriotypes deeply but unfairly associated with some identities is maintained and perpetuated .

\section{About the Authors:}

Brahim KHARTITE is a former ELT-supervisor and currently an Assistant Professor of ESP and soft skills at ENSAM MeknésMoulay Ismail University- Morocco. He holds PhD In didactics and Applied Linguistics- Teaching English as a foreign languagefrom the faculty of Education Rabat 2020.

Elhabib ELHADARI is the regional coordinator of the ELT supervision team in the region of Beni Mellal-Khenifra. He is a PhD holder and a certified PCELT trainer. He published his first book of poetry entitled "Bees in the Bonnet" in 2018

Abderrahmane BABNI is an assistant professor at the Polydisciplinary Faculty of Errachidia, Moulay Ismail University in Meknes, Morocco. He is a former Teacher supervisor. He hlods a PhD degree in Language, Culture and Communication from Moulay Ismail

\section{References}

[1] Aronson, et al. (2010).Social Psychology. 7th ed., Pearson Education, Inc.,

[2] Bauman, Z. (1996). From Pilgrim to Tourist- or a Short History of Identity. InQuestions of Cultural Identity (pp. 18-36). Sage.

[3] Edward W. (1994). Culture and Imperialism. New York: Knopf, 1994. Print

[4] Esteva, Gustavo, et al. (1998). Grassroots Postmodernism Remaking the Soil of Cultures. Zed Books,

[5] Foucault, M., Sheridan, A., \& Foucault, M. (1972). The Archaeology of knowledge

[6] Foucault, M. (1972). The archaeology of knowledge. Harper \& Row.

[7] Gerth, H. H., \& Mills, C. W. (1991). From Max Weber Essays in sociology. Routledge.

[8] Hartman, S. (2001). Preparing Modern Practitioners for Postmodern Families. In The Emergence of Family into the 21st Century (pp. 73-84). essay, Jones and Bartlett Publishers.

[9] Ikas, K. (2008). Crossing into a Mexifornian Third Space. In Communicating in the Third Space,(pp. 123-148). Routledge, New York.

[10] Said, E. W. (1994). Culture and imperialism. Vintage Books.

[11] Saidi, C. (2010). Women's authority and society in early East-Central Africa. University of Rochester Press.

[12] Sweet Briar "Empiricism: The influence of Francis Bacon, John Locke, and David Hume". College. Archived from the original on 8 July 2013. Retrieved 21 October 2013. 